\title{
Diagnosis and Treatment of Three-Rooted Maxillary Premolars
}

\author{
Hacer Deniz Arisu ${ }^{a}$
}

Tayfun Alacam ${ }^{b}$

\section{ABSTRACT}

Anatomical variations must be considered in clinical and radiographical evaluations during endodontic treatment. Access cavity modifications may be required for stress free entry to complex anatomy. Higher magnification and illumination can be useful for access cavity preparation and to recognize and locate additional canals. This article describes the diagnosis and clinical management of two clinical cases of three rooted maxillary premolars. (Eur J Dent 2009;3:62-66)

Key words: Three rooted maxillary premolars; Endodontic treatment; Diagnosis.

\section{INTRODUCTION}

The incidence of three-canalled maxillary premolars has been observed as 5 to $6 \%$ for first premolars ${ }^{1,2}$ and $1 \%$ for second premolars. ${ }^{3}$ Vertucci and Gegauff ${ }^{1}$ found $5 \%$ of 400 maxillary first premolars to have three canals: $0.5 \%$ existed as three canals in a single root, $0.5 \%$ existed as two canals in one root and one canal in a second root, and $4 \%$ existed as one canal in each of three separate roots. Carns and Skidmore ${ }^{2}$ found 6 of 100 maxillary first premolars to have three canals,

a DDs, PhD, Lecturer, University of Gazi, Faculty of Dentistry, Department of Operative Dentistry \& Endodontics, Ankara, Turkey.

b DDs, PhD, Professor, University of Gazi, Faculty of Dentistry, Department of Operative Dentistry \& Endodontics, Ankara, Turkey.

- Corresponding author: Hacer Deniz Arisu University of Gazi, Faculty of Dentistry, Department of Operative Dentistry \& Endodontics 8. Cadde 82. Sokak 06510 Emek, Ankara, TURKEY. Phone: + 905326461244 Fax: +90 3122239226 E-mail: hdenzayahoo.com; haceraggazi.edu.tr all of which existed as one canal in each of three roots. Vertucci et $\mathrm{al}^{3}$ found 2 of 200 maxillary second premolars to contain three canals.

Visualization of three-canalled maxillary premolars on preoperative radiographs can often be difficult. The earlier these complex root canal configurations are anticipated, the more likely one can properly manage intracanal preparation and filling procedures.

An awareness of root canal morphology and careful interpretation of preoperative radiographs is necessary for success in endodontic therapy. However, radiographs are two-dimensional images of a three-dimensional object. The clinician must be aware of these limitations during radiographic interpretation. . $^{4}$

Studies with various findings have been reported on the root canal types of maxillary first and second premolars. ${ }^{6-9}$ Maxillary premolars with three root canals were sometimes called small molars or 'radiculous' because of their 
similar anatomy to that of adjacent maxillary molars. ${ }^{10,11}$ In straight-on radiographs of maxillary premolars, Sieraski et al ${ }^{12}$ found that whenever the mesio-distal width of the mid-root image was equal to or greater than the mesio-distal width of the crown, the tooth most likely had three roots. Based on this information we diagnosed and proceeded with root canal treatment of two patients with three-canalled and three-rooted maxillary first and second premolars.

The use of the operation microscope by endodontists in United States increased from $52 \%$ in 1999 to $90 \%$ in 2007 . The operation microscope was used most frequently for rootend inspection, locating canal orifices, and root-end filling, respectively. ${ }^{13}$ The operating microscope appears to significantly increase the detection rate of second mesiobuccal canal in maxillary molars. ${ }^{14-16}$

\section{CASE REPORT 1}

A 24 year old male patient with a noncontributory medical history appealed the emergency clinic of University of Gazi Faculty of Dentistry Department of Operative Dentistry and Endodontics. He had a history of spontaneous pain. Clinically there was a deep amalgam restoration at the distal surface in the tooth 14 . The tooth was sensitive to cold and electronic pulp testing with responses indicating irreversible pulp damage. A preoperative periapical radiograph confirmed the presence of a carious lesion on the distal surface of maxillary first premolar (Figure 1). In the middle-third of the root a great mesio-distal width associated with complex root morphology was observed. The

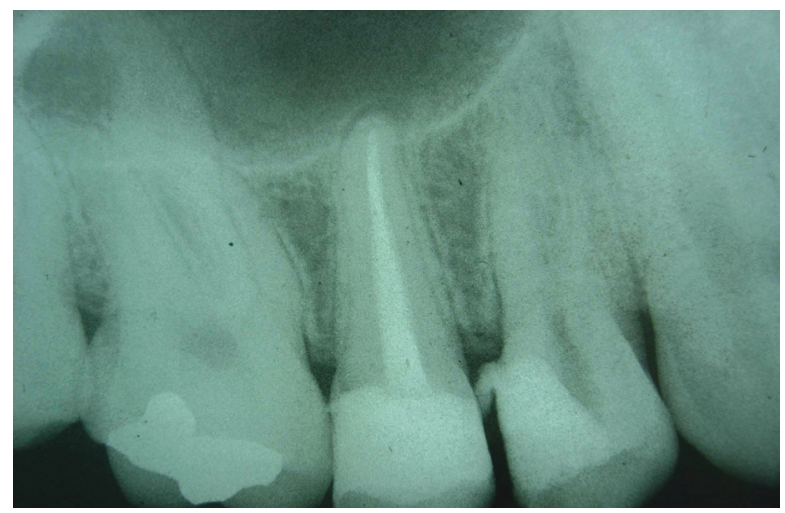

Figure 1. Periapical radiograph, showing the complex root morphology of the premolar suggesting the existence of three root canals. periapical radiograph of the opposite side had a similar anatomical conformation (Figure 2). The periapical region appeared radiographically normal. The tooth was isolated and access cavity was modified with a cut at the bucco-proximo angle from the entrance of the buccal canals to the cavo-surface angle resulting in a cavity with a T-shaped outline. Mesiobuccal and distobuccal canals were explored with size $10 \mathrm{~K}$ file (Zipperer, Germanyl and the palatal with a size $15 \mathrm{~K}$ file. The working length was established with apex locator (Root ZX, Morita, USA) and confirmed radiographically for each root (Figure 3). Coronal flaring was carried out with Gates Glidden (Densply Maillefer, Switzerland) burs, sizes 50, 70 and 90 . The remaining root canal system was prepared with K-files with copious irrigation using $2.5 \%$ sodium hypochloride solution. The master apical file in all canals was an ISO size 40. The canals were dried with paper points and obturated by laterally condensed gutta percha (Roeko, Germany) and AH 26 (Densply, Germany) root canal sealer (Figure 4). The treatment was completed in a single appointment.

\section{CASE REPORT 2}

A 32 year old male patient with a noncontributory medical history referred by Prosthodontics Department after removal of his bridge for endodontic treatment of his tooth 24 . $\mathrm{He}$ had a history of spontaneous pain. Clinically the pulp was exposed by carious lesion. No swelling or fistula was present. There was no evidence of periapical radiolucency. The tooth was isolated and access cavity was modified with a cut at the bucco-proximo angle from the

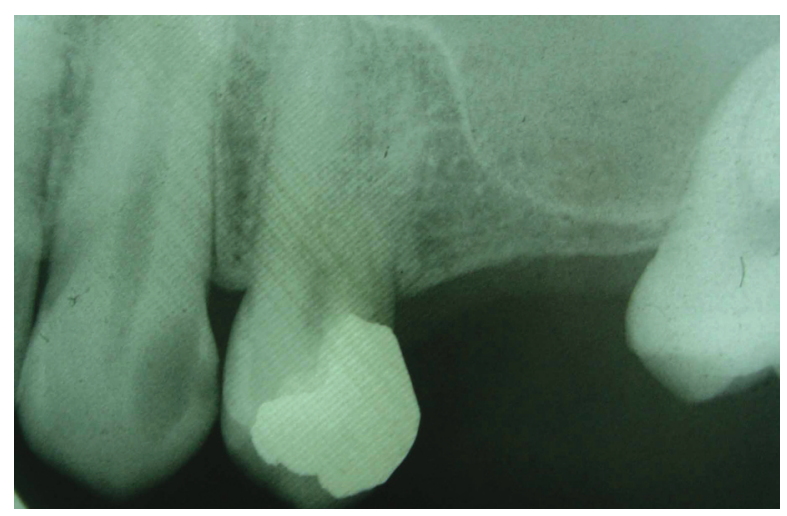

Figure 2. Periapical radiograph of the opposite side showing a similar anatomical conformation. 
entrance of the buccal canals to the cavo-surface angle resulting in a cavity with a T-shaped outline as described by Balleri et al ${ }^{17}$ (Figure 5). Access cavity was prepared and the floor of the pulp chamber was examined with an operating microscope at X8 (Moller-Wedel, Dento 300, Germanyl. Magnification revealed 3 orifices. After removing the coronal part, the buccal canals were explored with size $10 \mathrm{~K}$ file and the palatal with a size $15 \mathrm{~K}$ file resulting in clinical and radiographic confirmation of three canals suggested by the initial radiographic exam. The working lengths were estimated using an apex locator and then confirmed with a radiograph

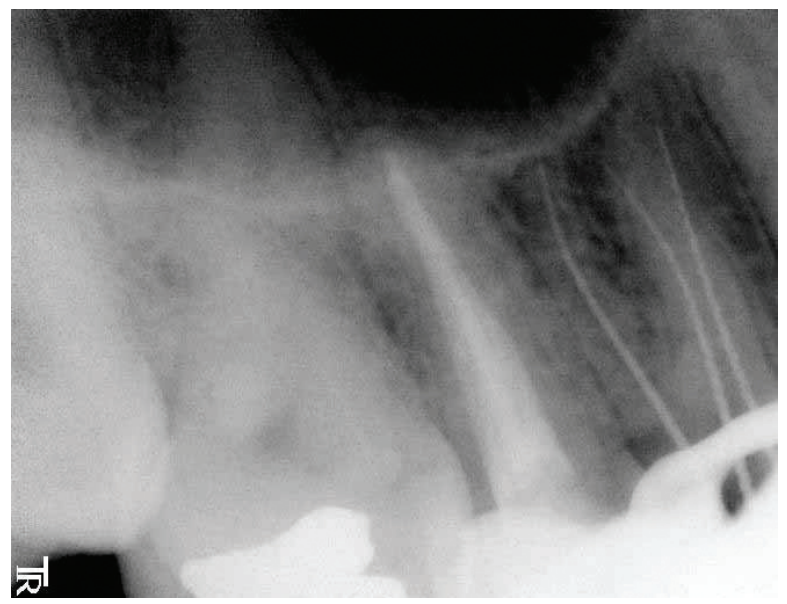

Figure 3. Radiographical confirmation of three root canals and determination of the working lengths.

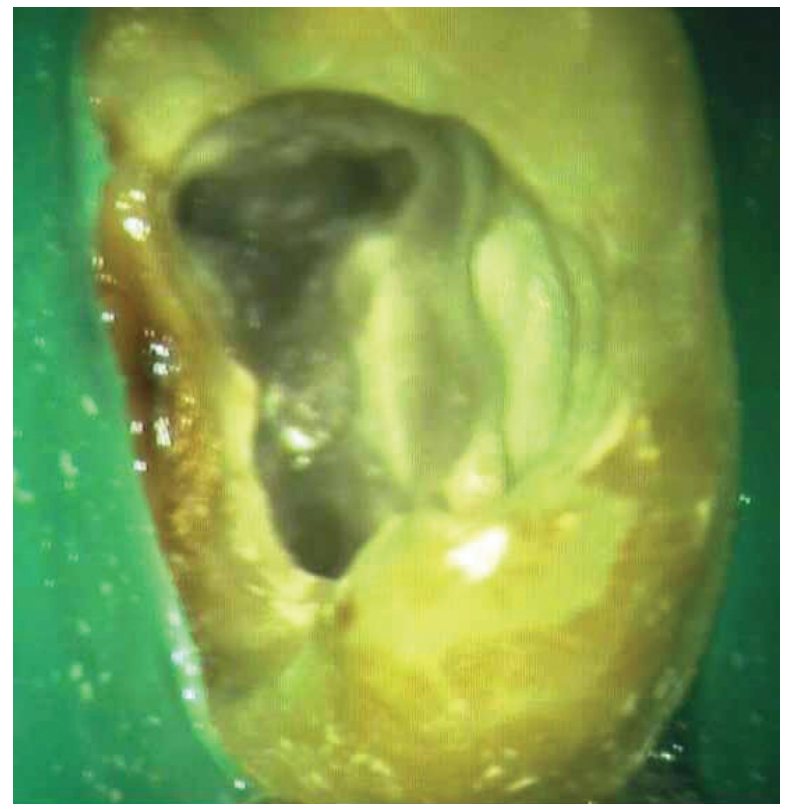

Figure 5. A picture of access cavity showing the triangular settlement of the three canal orifices.
(Figure 6). Coronal flaring was carried out with Gates Glidden burs, sizes 50, 70 and 90. The remaining root canal system was prepared with K-files with copious irrigation using $2.5 \%$ sodium hypochloride solution. The master apical file in all canals was an ISO size 40 . The canals were dried with paper points and obturated by laterally condensed gutta percha and $\mathrm{AH} 26$ root canal sealer (Figure 7). The treatment was completed in a single appointment.

\section{DISCUSSION}

The possible anatomic configurations of maxillary premolars are well documented in the

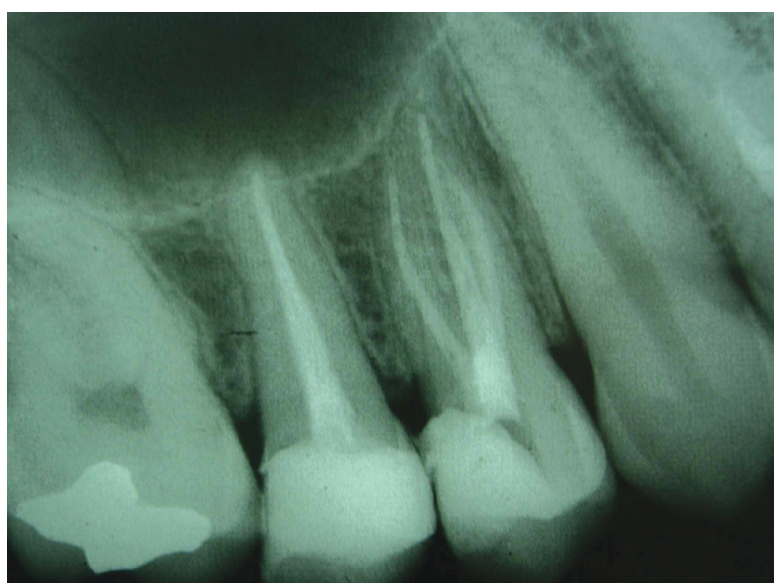

Figure 4. Periapical radiograph after obturation of the three root canals.

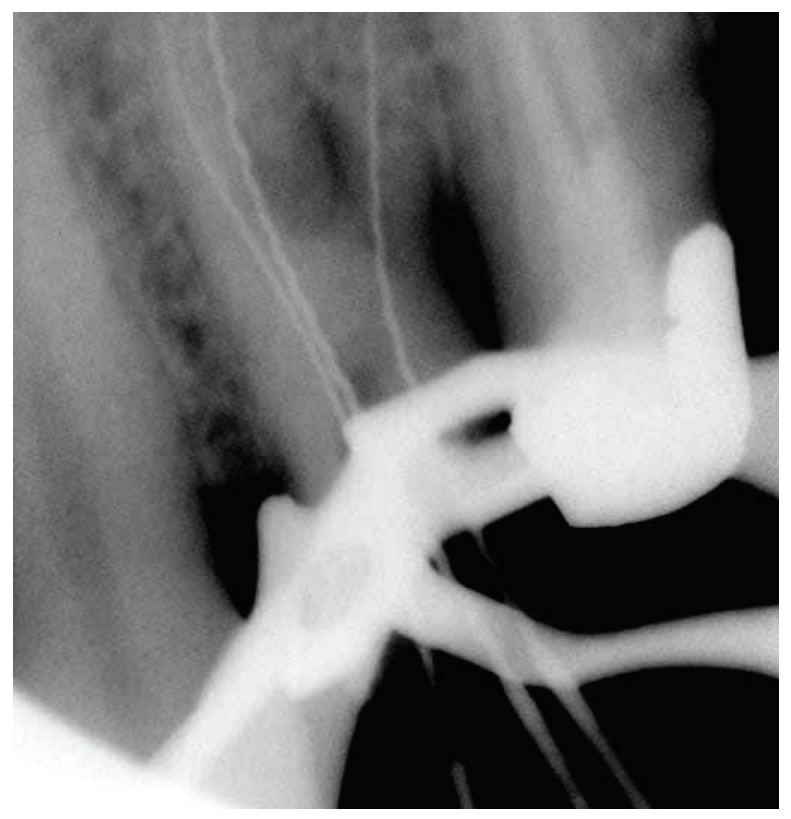

Figure 6. Radiographical confirmation of three root canals and determination of the working lengths. 
literature. High quality preoperative radiographs and their careful examination are essential for the detection of additional root canals. ${ }^{18-20}$ Walton ${ }^{21}$ recommended the use of two diagnostic radiographs. If a radiograph shows a sudden narrowing or even a disappearing pulp space, the canal diverges at that point into two parts that may either remain separate or merge before reaching the apex. ${ }^{22}$ If an eccentric orifice found, at least one more canal is present and should be searched for on the opposite side.1 A third canal should be suspected clinically when the pulp chamber does not appear to be aligned in its expected bucco-palatal relationship. Additionally, if the pulp chamber appears to deviate from normal configuration and seems to be either triangular in shape or too large in a mesiodistal plane, more than one root canal should be suspected. ${ }^{23}$ Pulp cavity of each tooth shows high variability that makes the endodontic treatment unique. In three rooted maxillary premolars, the buccal orifices are close to each other that are hard to locate.

When confronted with unusual tooth anatomy as three rooted maxillary premolars, good illumination and magnification can make treatment easier. With the aid of an operating microscope or loop it is possible to locate all the root canal orifices. Carr ${ }^{24}$ affirms that the operating microscope has greatly improved the ability of the endodontist to visualize and treat periapical pathology in endodontic surgery. It

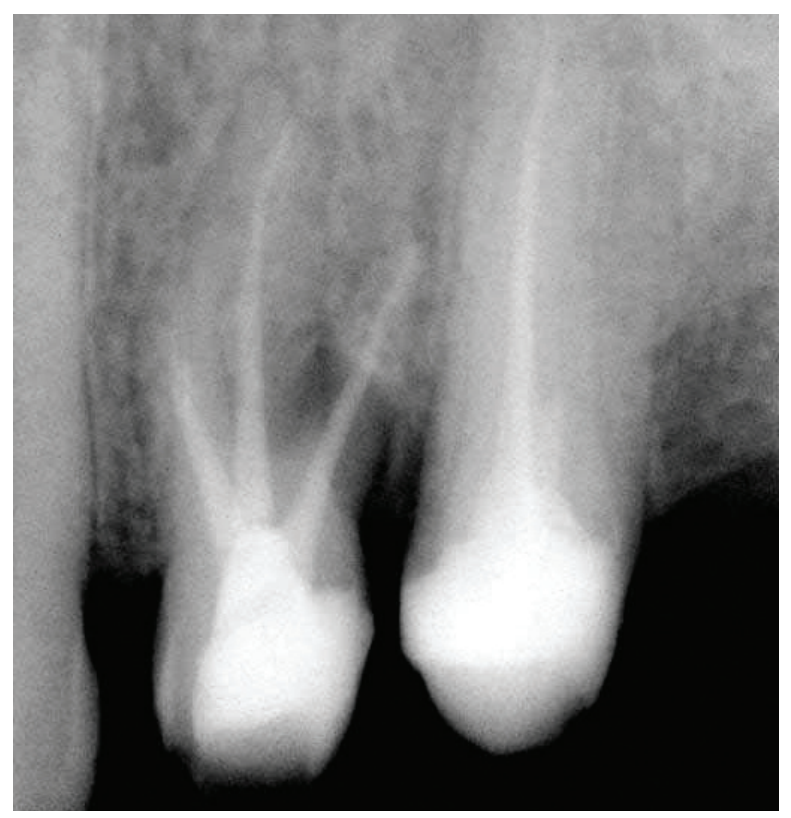

Figure 7. Periapical radiograph after obturation of the three root canals. has also enhanced the practice of nonsurgical endodontics. The higher magnification and illumination can be useful for access cavity preparation, instrumentation and obturation. It can improve the clinician's view of the complexity of the root canal anatomy and aid in the location of additional canals. ${ }^{25}$

The outline of the access cavity was shaped by a cut at the bucco-proximal angle from the entrance of the buccal canals to the cavo-surface angle, as suggested by Balleri et al. ${ }^{17}$ This T-shaped access outline is helpful for correctly reaching all of the root canals.

An apex locator was used to estimate the working lengths prior to establishing a working length estimation radiograph. The use of an apex locator improves the chances of estimating the correct length first time, especially when canals are likely to be superimposed on a radiograph.

\section{CONCLUSIONS}

Morphological variations in pulpal anatomy must be always considered before beginning treatment. Careful clinical and radiographical examination is essential for successful endodontic treatment. Use of an operating microscope or loop can enhance the visualization of the pulp chamber and extra canal orifices.

\section{ACKNOWLEDGEMENT}

First case report was presented at "6. Aegean Region Chambers of Dentists International Scientific Congress and Exhibition, 2006" and second case report was presented at "7. Aegean Region Chambers of Dentists International Scientific Congress and Exhibition, 2007".

\section{REFERENCES}

1. Vertucci FJ, Gegauff A. Root canal morphology of the maxillary first premolar. J Am Dent Assoc 1979;99:194-198.

2. Carns EJ, Skidmore AE. Configurations and deviations of root canals of maxillary first premolars. Oral Surg 1973;36:880-886.

3. Vertucci F, Seelig A, Gillis R. Root canal morphology of the human maxillary second premolar. Oral Surg 1974;38:456464.

4. Fishel D, Tamse A. Dentists' mistakes in making correct radiographic diagnosis. Quintessence Int 1978;6:59-64. 
5. Ingle Jl, Walton RE, Lambert GL, Lambert C, Taintor $J F$, Zidell JD, Beveridge EE. Preparation for endodontic therapy In: Ingle Jl (ed) Endodontics. $3^{\text {rd }}$ ed. Philadelphia: Lea\& Febiger; 1985:54-101.

6. Mueller AH. Anatomy of the root canals of the incisors, cuspids and bicuspids of the permenant teeth. $J$ Am Dent Assoc 1933;20:1361-1386.

7. Pineda F, Kuttler Y. Mesiodistal and buccolingual roentgenographic investigation of 7,275 root canals. Oral Surg 1972;33:101-110.

8. Bellizi R, Hartwell G. Radiographic evaluation of root canal anatomy of in vivo endodontically treated maxillary premolars. J Endod 1985;11:37-39.

9. Caliskan MK, Pehlivan Y, Sepetcioglu F, Turkun M, Tuncer SS. Root canal morphology of human permanent teeth in Turkish population. $J$ Endod 1995;21:200-204.

10. Malibaum WW. Endodontic treatment of a 'radiculous' maxillary premolar: a case report. Gen Dent 1989;37:340341.

11. Goon WW. The 'radiculous' maxillary premolar: recognition, diagnosis, and case report of surgical intervention. Northwest Dent 1993;72:31-33.

12. Sieraski SM, Taylor GT, Kohn RA. Identification and endodontic management of three-canalled maxillary premolars. J Endod 1985;15:29-32.

13. Kersten DD, Mines P, Sweet M. Use of the microscope in endodontics: results of a questionnaire. $J$ Endod 2008;34:804-807.

14. Stropko JJ. Canal morphology of maxillary molars: clinical observations of canal configurations. J Endod 1999;25:446450.

15. Buhrley LJ, Barrows MJ, BeGole EA, Wenckus CS. Effect of magnification on locating the MB2 canal in maxillary molars. J Endod 2002;28:324-327.

16. Alaçam T, Tinaz AC, Genç O, Kayaoglu G. Second mesiobuccal canal detection in maxillary first molars using microscopy and ultrasonics. Aust Endod J 2008;34:106-109.

17. Balleri P, Gesi A, Ferrari M. Primer premolar superior com tres raices. Endod Pract 1997;3:13-15.

18. Slowely RR. Radiographic aids in the detection of extra canals. Oral Surg, Oral Med Oral Pathol 1974;37:762-772.

19. Slowely RR. Root canal anatomy- road map to successful endodontics. Dent Clin North Am 1979;23:555-573.

20. Javidi M, Zarei M, Vatanpour M. Endodontic treatment of a radiculous maxillary premolar: a case report. J Oral Sci 2008;50:99-102.

21. Walton RE. Endodontic radiographic techniques. Dent Radio Photoradio 1973;46:51-59.

22. Vertucci FJ. Root morphology of mandibular premolars. $J$ Am Dent Assoc 1978;97:47-50.
23. Al-Fouzan KS. The microscopic diagnosis and treatment of a mandibular second premolar with four canals. Int Endod $J$ 2001;34:406-410.

24. Carr GB. Microscopes in endodontics. J Calif Dent Assoc 1992;20:55-61.

25. Coutinho Filho T, La Cerda RS, Gurgel Filho ED, de Deus GA, Magalhães KM. The influence of the surgical operating microscope in locating the mesiolingual canal orifice: a laboratory analysis. Braz Oral Res 2006;20:59-63. 